dicitis in chuldren immediate operation shoud be adrised. No matter what the stage of the disease may be, I leel it much wiser to operate at once, and not delay in hopes that at a later date an interval operation may be performed. This advice is in aecord with that of many surgeons lor appendicitis at any age, but, as alrady expressod in this paper, 1 an not entirely in accord with such vews, except in cases of children. 'The oluler the pationt the less tendency there seems to me to be to spreading peritonitis, and the nore unfarorable are the results of operation in grave cases.

Iy own experience with operations for general septic peritonitis has demonstrated to my own satisfaction that the results of the operation on young adults. if they be rapidly peformed, are apt to be tavorable, while those on patient: orer to or tis are almost invariably tatal.

1 thought it might be of interest to give the age statistics of 1.000 calses of appendicitis, at the time of their operation. While my operative cases number more than this, I have not included those of the last few months, is a round number like 1,000 seemed to me more conrenient. I have also tabulated in 1,500 cases which I have personally secen, the ages at which, as far as could be ascertained, the first symptoms of inflammation of the apperetix manifested jtself.

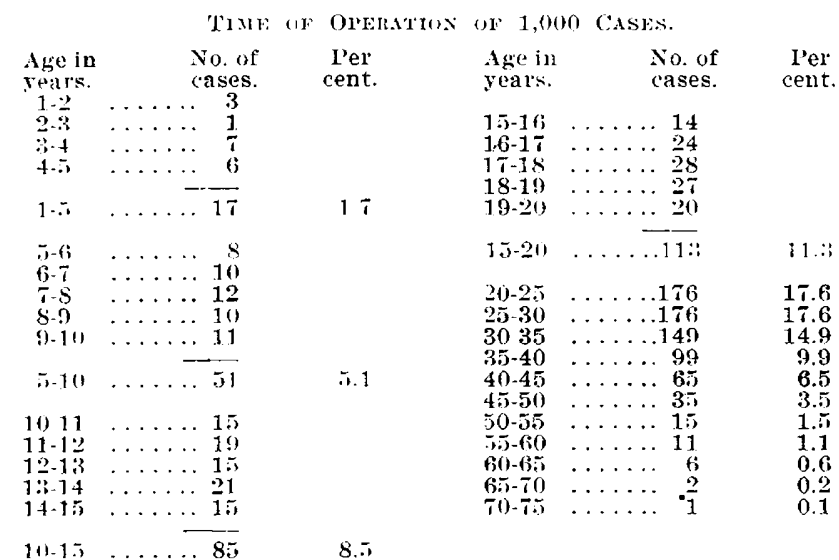

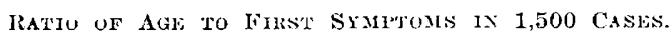

The proportion which had the first symptoms in the first year $i$ : .111:3 per cent. of all cases.

In first $\triangleq$ years $\ldots \ldots \ldots \ldots \ldots \ldots \ldots \ldots \ldots \ldots \ldots$

In first 5 years...........

in first 10 vears....................

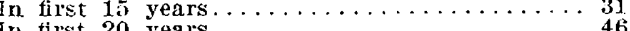

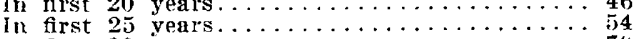

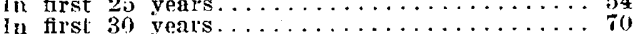

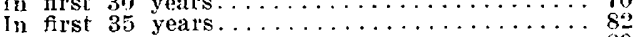

In first ${ }_{40}$ years. $\ldots \ldots \ldots \ldots \ldots \ldots \ldots \ldots \ldots \ldots \ldots \ldots, 89$

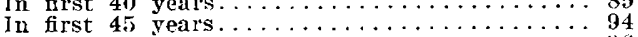

In first 50 years. $\ldots \ldots \ldots \ldots \ldots \ldots \ldots \ldots \ldots \ldots \ldots \ldots \ldots$

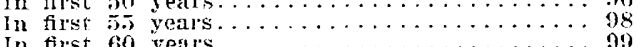

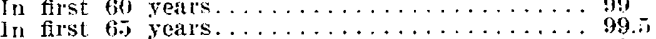

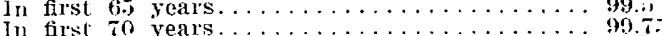

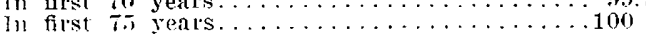

From these statisties it will bo seren that young adnt li i.. furmishes the largest numiber of eases of appendicitis. In those that demanded operation, the greatest number newrud between the ages of 20 and 35 . the prountion hoing over 50 per cent. After 35 the jroportion of whes bomes rapidly and progressively smaller, bemorn 1 th and 50 being but 10 per cent.

lectore the age of 20 , the proportion is $26 \%$ per (ont.; befo:c the age of 15 years, 15 per cent ; before the are of 10 years, .068 per cent. The youngest cases in my series were $12,121 \%$. 16 and 20 months. respectiwely. Over 60 years. the proportion was nearly 1 ner mint. (ong). The oldest case was reto goars.

\section{'THE DIAGNOSIS OF APPENDICITIS.}

SHOULD THE APPENDIX BE REMOVED WHEN THE ABDOMEN IS OPEN FOL OTHER CONDITIONS? * FLOYD W. MCRAE, M.D.

ATLANTA, GA.

So much has been written and said about the case of diagnosing appendiceal discase, so little stress has been laid on the occasional difficulty of making a correct diagnosis, that condemnation is heaped on those who fail to appreciate the real condition. Sight is lost of the fact that the best diagnosticians and abdominal surgeons are occasionally put to it to determine whether the appendix is the seat of the trouble or not. Mistakes are made by the very best surgeons. Each of us should profit by his own mistakes and the mistakes of his fellows, and each of us shouid be willing to give the whole profession his experiences, fairly and unreservedy.

1 have only removed $2 \% 2$ appendices of which I have iccurate records. In forty instances, multiple operations were done at the same seance, and in many of them the diseased condition of the appendix was not dennitely diagnosed before opening the abdomen.

In 71 of these cases appendiceal disease was associated with or maslied by one or more of the following conditions: In 4 cases by renal calculi; in 5 cases by gallstones or gall-bladder adhesion; in 18 cases by rague symptoms of indigestion, biliousness and indefinite colic; in 5 cases by frequently recurring dysentery or rectal disease; in 3 cases by acute intestinal obstruction, and in 2 cases of typhoid ferer; in 12 cases by floating and discased kidneys; in 1 caso by acute septic n'phritis; in 1 case by retroperitoneal tubercular abscess; in 3 cases by tubercular peritonitis; in 11 cases by marked menstrual disturbances; in 11 cases by discase of the uterine appendages; in 2 cases, retrocecal l:crnice were mistaken for appendicitis, the appendices only becoming involved incidentally. In 2 other cases 110 diagnoses were made, but exploratory operations demonstrated appendiceal disease. In 1 case, in a roung girl, a ruptured dermoid cyst was diagnosed appendicitis, and in another, a right salpingitis was diagnosed appendicitis.

I have done at one sitting, on the same patient, without unusual shock or prolonged convalescence, the following operations: Dilatation of the cervix and curcttement of the uterus, removal of a number of enlirged cervical glands and hemorrhoids, anchoring a Hoating kidney, and removal of a riseased appendix. It another time I removed at the same sitting a diseased appendix, and did a gastroenterostomy for contraction of the pylorus ensequent on gastric ulcers two vears before.

In the process of erolution. medicine and surecry have reached a stage of rovelopment when such terms as colic gastralgia, acute indigestion and intestinal indigestion ean no longer be loosely used in diagnosis without subjecting the user to just eritjeism. Ther are but symptons of some refinite chemic or mechanic defect in the digestive process, and careful investigation would reveal the underlying pathologs, i. e. a contracted pylorus, gallstones or appendiceal disease, or partial intestinal obstruction from old adhesions.

Since Fdebohls, Deaver and other leading members of the surgical side of the profession called attention to

* Read at the Fifty-fifth Annual Session of the American Medical Association. in the Section on Surgery and Anatomy, and approved for publication by the Executive Committee: Drs. DeForest Willard. Charies A. Powers and .J. E. Moole. 
the frequent association of appendiceal and pelvic inflammatory disease, a vigorous discussion has been waged pro and con, the one side claiming that inflammatory disease of the appendix is apt to involve the uterine appendages, and that disease of the appendages is often the direct cause of inflammatory appendiceal disease, while the other side argues with equal zeal that the conditions are separate and distinct and seldom corelated. They hold, therefore, that the appendix should not be interfered with when bound up in adhesions due to pelvic inflammatory disease, and that the freed appendix is not likely to give future trouble.

\section{REMOVAL OF APPENDIX DURING OTHER OPERATIONS, INCLUDED IN CLASS 1 TO 13.}

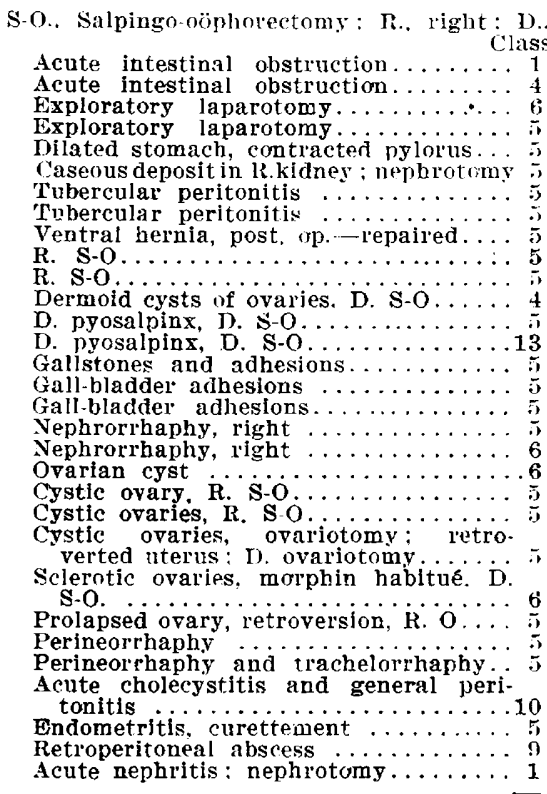

Total

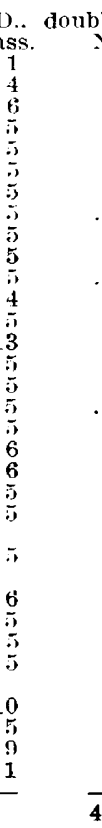

clinical experience, and is conducive to incomplete surgery and unsatisfactory results.

Kelly, in his classical work on gynecology, gives the opinions of a number of the leading surgeons and gynecologists in this country on this question. Most of them were of the opinion that the removal of the appendix, unless markedly diseased, should not be a routine practice, the author agreeing with these.

The by-no-means infrequent incomplete cures following pelvic operations where appendices have burn left, condemning the victim to chronic invalidism, the ever-present anxiety and danger of a severe and fatal attack of appendicitis, have impressed me with the advisability of removing the appendix during all pelvic operations when it shows the least evidence of disease, or when it is accessible and ean be removed without undue prolongation of the operation or hazard to the pat tient.

Had I an appendix, I would feel that any surgeon opening my abdomen and leaving the organ, if accessible. had grievously sinned against me. I entertain this same feeling and a similar opinion for members of my own family. Holding such an opinion, entertaining such a leoling for my own loved ones, could I advocite less for the loved ones of others. Nowhere is the Golden Rule more applicable than in surgery, and the surgeon who does more or less for those who subuit their health and lives unreservedly to his skill and honor than he wovld want done fol him or his, under similar circumstances, is recreant to the trust reposed in him, and is unworthy the respect and confidence of honest men and women.

CAse 1.-Mrs. P. W. G., 25 years old. Gave history of hav. ing ovaries removed per raginam one year ago. Since then has had repeated light attacks of pain in the McBurney region and in right side of pelvis. Chronic indigestion for several years. At times has a dragging sensation over right kidney. Adinitted to St. Joseph's Infirmary june 26, 1903. Has marked tenderness over appendix; slightly movable right kidney: uterus free, it and cervix being atrophied.

Operation.-.June 30. 1903. Gas-ether. MeBurney gridiron incision; appendix found in pelvis: was thickened, very much enlarged, and attached by sniall adhesions. Doyen amputation. Layer closure.

Case 2.-Miss E. S., 35 years old. Negative family history. Yenstruation began at 13 years, was regular but always painful, so a curettement was done eight years ago. For the past. four or five years she has suffered for five days before and five days after menstruation, with often severe pains over left ovary. A double salpingo-öphorectomy, June, 1903, relieved her of all pelvic pain. Dysentery from November to February nine years ago. For years she has had general colicky pains lasting from a few hours to a day or so. Two years ago was in bed a month with "bilious" colic and suffered great abdominal pain. Five months after ovaries were removed she was taken with pain in epigastrium, which became localized in a few hours to appendiceal region. Since then any jolting or $\mathrm{ex}$ ercise caused pain in the left iliac region. A similar attack began ten dars ago and pain continued until admitted to $\mathrm{St}$. .Joseph's Infirmary March 25, 1904.

Operation.-March 28, 1904. Gas-ether. McRae transverse incision with longitudinal opening of peritoneum, enlarged by a transverse cut. There were thick, dense adhesions of omentum, passing from cecum into pelvis to stump of removed ovary; a retrocecal appendix was dissected out of adhesions by working over and behind border of friable cecum. Appendix tore out of cecum, its lumen being closed. This umbilication was covered over by peritoneum and adhesions, a cigarette drain being earried to this point. Peritoneum closed with No. 1 catgut. silkworm gut being used for the remainder. Very little discharge followed. patient going home well April 25. 
CASE 3.-Mr. W. L. J., 30 years old; traveling salesman. IIistory of typhoid at 7 , xheumatism at 10 years of age. From tive to two years ago he had a diarrhea each spring, ending in a dysentery, all lasting from five to eight weeks, being confined to bed three or four days with the latter. Eighteen months before operation he awoke with slight pains in appendiceal region, which soon went to left iliac region and passed off in about five hours. No nausea or soreness. In two months a similar attack, lasting six hours, another in two months lasting eight hours, etc., an attack about every two months, 'ach getting a little longer. Never any nausea or soreness after the third day, until six months ago, when he was in bed ien days with nausea, marked pain in the McBurney region, with a spasmodic pain in rectum, penis and perineum. Was sore for a week thereafter. Similar attack, lasting six days, two months later, with daily formation of gas in cecum since. Under stomach specialist for weeks, without relief.

Admitted to St. Joseph's Infirmary Aug. 14, 1902. Appendix rould be felt (?) with thickening of cecum; urine contained a lew casts.

Operation.-Aug. 21, 1902. Gas-ether. McBurney gridiron. Omentum and large intestine only found at wound. A median incision was made, when stomach and transverse colon came into wound: the latter could not be traced to the left, but seemed to enter pelvis on the right side. At first, no small intestine was found; was later located matted in pelvis and collapsed like an obstruction. Tracing the bowel for a short distance, a small Meckel's diverticulum was found; beyond this intestine was thickened, rough, granular. looked tuberculous. and soon became firmly fixed in pelris surrounded by adhesions, so could not be brought up.

Through the McBurney wound, appendix was found in pelvis surrounded by adhesions. Doyen amputation done. Everything bled freely. Abdomen flushed with saline and each wound was closed in layers, a cigarette drain being placed in the lower angles.

Patient very much depressed for twenty-four hours. Rallied and made uneventful recovery. In two months weighed more than ever before.

CASE 4.-Mrs. H. V. J., 41 year's old. Family history good. Oldest child 23 years. Was in labor twenty-four hours; placenta adherent to right side and had to be removed: was very sick for several days following. Never strong thereafter, having a dragging sensation in lower abdomen and pain when wishing to defecate instead of normal reflex. Second child 21 years old. Had hemorrhage after labor and was in bed five weeks. Two years later menses became irregular and she aborted at three weeks; was weak and had a leucorrhea thereafter, and when she walked, hemorrhage returned. Two years after abortion was in bed three weeks, at beginning of pregnaney, from weakness. Three months prior to labor, was "swollen all over" and could not lie down on account of diffcult breathing. Four years after this labor was in weakened condition, when lacerated cervix and perineum were repaired, she becoming very much better, but could not walk long at a time. Was told she had prolapsus uteri. For past seventeen years menses have been regular, but she always had a dragging in pelvis and acute, general abdominal pain, which came on irrespective of quietude and lasted one to three hours, being relieved by a hot douche, enema or hot applications to abdomen. One year ago was in bed a day with acute pain over appendix and thereafter had a tearing pain in appendiceal region, when she rested on left side; much walking would also cause it.

Present Illness.-On April 21 was taken with acute pain in the McBurney region, which increased until relieved by morphia six hours later. In another six hours pain had returned and inereased until bowels acted.

Admitted to St. Joseph's Infirmary April 23, 1903. Temperature 100 , pulse 85 , nauseated, weak, tender over right side of abdomen. Rectal feeding until operation, May 10.

Operation.-Gas-ether. Considerable débris from curettement. Laparotomy. Appendix found adherent to right ovary and tube; was much enlarged, brawny, tearing from slightest pressure. Appendix was too rotten to make cuff, so a chromicized catgut ligature was tied about same, end cauterized and stitched over. Right tube enlarged and thickened; ovary was a cyst, size of an orange; both were removed, the raw surface being closed over and stump stitched to abdominal wall to support the retroverted uterus. Layer closure. Uneventful recovery.

"Now in better health than in twenty years."

CASE 5.-Mrs. D. R. W., 33 years old. Bilious fever and later dysentery, seventeen years ago. Eighteen years ago she fell six feet and was unconscious for several hours and menstruation was delayed for six months. For twelve years after marriage she had a continuous leucorrhea, which was profuse at times. During summer of 1899 she had abscess of both vulvo-vaginal glands, followed by severe pain over left ovary, which continued, at intervals, until the fall, when an application of tincture of iodin and carbolic acid was made to interior of uterus. Peritonitis resulted, confining her to bed for two months, opiates being used to relieve pain. In January, 1900, left pyosalpinx was removed, after freeing adherent intestines, which formed a roof to that part of the pelvis. Was in good health then for a year, when she had la grippe, and tuberculosis was suspected.

Present Illness.-For two or three years has had attacks of pain in right kidney, lasting from two to three days. For: a year these have been frequent, with almost constant aching, pain being relieved when she replaced the floating kidney. Has eaten little for the past two years. The smallest amount of food causes pain in right hypochondriacal region.

Operation.-March 29, 1904. Curettement, and sphincter di vulsed. Ferguson incision and delivery of right kidney, which was large, hard, and capsule firmly adherent. Posterior flap of capsule stitched to muscles and anterior flap sutured between edges of wound, which was closed with silkworm-gut suture, a cigarette drain being used.

A McBurney gridiron incision was then made, when the cecum and a long appendix, surrounded by adhesions, were found under the border of the liver, the colon passing to left hypo. chondrium, thence to right iliac region and into pelvis. Layer closure and uneventful recovery.

CASE 6.-Mrs. J. C. H., 35 years old.

History. - Since she can remember, has had a chronic laryngitis. Always a dysmenorrhea, which was not so bad after first child, which is 11 years old. Has had hemorrhoids, almost a continuons leucorrhea and backache since birth of this child. During second pregnancy, eight years ago, she had a violent pain, like colic, in right side of abdomen; a mass soon developed in the right iliac region which was pronounced a "tubal abscess," which later "discharged through uterus" while she was preg. nant! She was in bed nearly a year. At times since, has felt this mass in side of abdomen; had frequent attacks of colic, thought to be ovarian, but was conscious of two distinct kinds. Nausea, but no vomiting. Has not been able 10 walk much for several years on account of pain, and riding was torture. Amputation of cervix and ligation of piles one year ago.

Admitted to St. Joseph's Infirmary Jan. 13, 1904. Had right floating kidney and tenderness over appendix.

Operation.-January 14. Gas-ether. Ferguson incision and delivery of right kidney; posterior flap of capsule sutured to muscles, anterior flap brought between edges of wound. Silkworm-gut closure, with drainage. McBurney gridiron incision. Appendix found in pelvis, surrounded by adhesions and strictured near base. Doyen invagination amputation, raw surface closed over and wound closed in layers.

These appendices ought to have been removed when the first operations were done, and might have been without difficulty, and far less danger than submitting to second operations necessitated. The patients would have been cured, and the operator would have saved himself the discredit of "successful operations that failed to cure the patient."

While laying more stress on removal of the appendices before closing the incisions after pelvic operations, 
I also want to put on record as holding the same view with reference to other abdominal operations. How often is the focus of infection that lights up gall-bladder disease an inflamed appendix! The frequent association of chronic appendicitis and movable kidney is now so well recognized as to hardly require mentioning.

Where the two pathologic conditions obtain, the correction of one seldom cures the other. If I am not mistaken, I did the first combined operation for removal of the appendix and the anchoring of a movable kidney through the same incision. I reported two cases before the meeting of the Southern Surgical and Gynecological Association in Atlanta. Both the cases then reported have been kept under observation, and both seem to have been perfect cures.

I have latterly, however, preferred to make separate incisions for each operation, as it requires little more time. and the work can be much better done.

\section{FACTORS IN THE MORTAIATY OF APPENDICITIS.*}

JOHN B. DEAVER, M.D.

Surgeon-in-Chief, German Hospital. PHILADELPHIA.

Infectious inflammation of the vermiform appendix has occupied the attention of the medical profession for many years, has been discussed and debated at hundreds of society meetings, and has furnished a fertile theme for thousands of good, bad and indifferent medical authors. Books have been written on the subject in France, in Germany, in England, and in the United States describing the historic episodes, the pathology, the diagnosis and the treatment of the disease.

The vermiform has been cut off, tucked in and turned inside out; the patients have been purged, narcotized, packed in ice or baked in poultices; they have been starved or instructed to walk on all fours like quadrupeds; leucocytes have been gazed on through the barrel of the microscope and tested for glycogen, and the urine assiduously examined for indican, acetone or albumin, and yet, with all this study, all of the examinations, a fatal appendicitis caused by a little $8 \times 1 \mathrm{~cm}$. organ has doomed thousands of suffering humanity to an early and untimely end. The lack of common sense and ordinary intelligence in eliciting the history of the attack or the neglect of the use of the only instrument of any service in the diagnosis of this disease, the palpating hand of the practitioner, is responsible for much of the mortality.

\section{ERRORS IN DIAGNOSIS.}

Errors in diagnosis are to be considered under two headings:

1. The time that elapses between the onset of the disease and the production of sufficient symptomatic reaction to attract the attention of the patient.

2 . The delay of the physician himself in reaching a diagnosis.

In regard to a period of latency, it is undeniable that in a few cases the most prompt diagnosis and early operation discloses advanced pathologic changes, with a thin, seropurulent fluid throughout the peritoneal cavity. The appendix may show little macroscopic evirlence of disease, or may be perforated and gangrenous. Many of these patients recover, some of them die, and

* Read at the Fifty-fifth Annual Session of the American Medical Association, in the Section on Surgery and Anatomy, and ap. proved for publication by the Executive Committee: Drs. DeForest Willard. Charles A. Powers and J. E. Moore. in the latter event neither the practitioner nor the surgeon can be reproached for an error in judgment. T'ley were operated on at the time of election, and were the few exceptions to the rule. Some patients suffer habitualiy from colicky pain in the abdomen, due to intestinal fermentation and the accumulation of flatus; some women suffer abdominal pain at the menstrual epoch; many patients have aequired the too ready nabit of using laudanum or paregoric for every abduninal ache or pain, and especially when the sufferer is a child.

In such the onset of serious symptoms may not have given warning that something unusual and more severe has occurred until the disease has advanced into the later stages. It is the duty of the practitioner to continually and persistently impress on his patients the danger that lies in the uncontrolled use of opiates, particularly in children, in whom the percentage of the more severe grades of appendicitis is greater than in adults.

The failure to make an early diagnosis of acute appendicitis is responsible for most of the factors entering into the mortality of the disease. With a nearly unanimous agreement among experienced surgeons that operation is indicated in the early hours of the attack, the great importance of prompt diagnosis can be clearly perceived.

In every sudden abdominal pain the probability of an appendicitis should be borne in mind, and no other diagnosis considered until that disease can definitely be excluded.

In abnormal position of the appendix may make the diagnosis difficult at times, and in certain of the lulminating types when there is a very obscure history, it is often difficult to locate the source of the peritoneal infection. Salpingitis, cholecystitis, perforated gastric ulcer, acute pancreatitis, intestinal obstruction, mesenteric thrombosis, enteric fever, basal pneumonia, diaphragmatic pleurisy and a few other conditions are often confused with appendicitis; but the history, the onset and the sensation experienced by the palpating hand will usually differentiate the true condition.

The subject of the differential diagnosis is outside the province of this paper.

In children abdominal pain is of such common oceurrence that an appendiceal colic is very apt to be unrecognized. This is especially true in the first year of infancy, and cases with comparatively mild local sy?nptoms are certainly rarely diagnosed. If the process goes on to abscess formation, the condition is more readily discovered if the possibility of an appendicitis is not forgotten.

One of the greatest fallacies which has ever been propagated to account for appendiceal symptoms is rheumatism. In an extensive experience with appendicitis I have always found true appendiceal symptoms to be due to a diseased appendix in every case, even where rheumatism has been held responsible for the symptomcomplex prior to operation. Without dilating further on the diseases that may be diagnosed when appendicitis is the true lesion, it may be well to consider why such confusion continually arises.

Acute appendicitis in the great majority of cases is easy of perception, even in the earliest stages. The disease is so prevalent, the cases observed by every practitioner of medicine so numerous, that one can but wonder at the continuous stream of pus-bearing abdomens that flow into a large hospital yearly. Every physician 